\title{
EL SISTEMA PROSÓDICO ESPAÑOL VENEZOLANO
} PROSODIC SYSTEM OF VENEZUELAN SPANISH

Recibido: 08-01-07

\section{RESUMEN}

Este trabajo se llama 'Sistema Prosódico' para incluir ambos acentos en español: el prosódico y el ortográfico. Todas las palabras de contenido y de forma portan un acento en una de sus sílabas por ser un idioma de acentuación silábica. Las palabras de contenido y forma se clasifican como agudas, graves / llanas y esdrújulas por la posición del acento en una sílaba dada. En homófonos y homógrafos verbales, el acento distingue tiempo verbal / temporalidad, modo y persona. Igualmente, sirve para distinguir oposiciones entre los pares 'nombre / verbo' y 'nombre /adjetivo' en homófonos y homógrafos. Esta característica sistemática del español se presenta en un cuadro. También se incluye en el estudio la relación existente entre prosodia y entonación que complementa la pronunciación, semántica y sintaxis de las palabras en contexto o aisladamente. Se ofrecen ejemplos ilustrativos de cómo funciona la entonación en español venezolano.

Descriptores: acento, sistema, entonación.
Ángel Milano ${ }^{1}$ UPEL- IPB

La Real Academia Española en su 'Gramática de la Lengua Española’ (1931) tiene un capítulo dedicado a la acentuación de las palabras en español. En éste se asevera que para el uso de los acentos hay que considerar lo que la Prosodia - parte de la Gramática que enseña la recta (sic) pronunciación y acentuación de las letras, sílabas y palabras establece:

(...)que en nuestras dicciones castellanas puede cargar la pronunciación, ya en la última ya en la penúltima, ya en la antepenúltima sílaba; como en este ejemplo: citará, citara y cítara. A la primera de estas tres clases llamaremos ‘agudas'; a la segunda, 'llanas o graves’ y a la tercera, 'esdrújulas’. También hay las llamadas 'sobreesdrújulas', y son las que llevan el acento hasta tres y aun cuatro sílabas antes de la última; como fériamela, dábasemelo.

This study is called 'Prosodic System' in order to include both types of Spanish stresses: the prosodic and the 'orthographic' All content and form words bear some kind of stress because it is a syllable stressed language. Spanish homophone and homographic content words are classified as oxitone words (agudas), paroxitone words (graves / llanas), and proparoxitone words (esdrújulas) by the position of stress in a given syllable. Stress distinguishes tense/time, mood, and person in verbal homographic and homophone words. It also establishes semantic and class oppositions among the pairs 'noun / verb', and 'noun / adjective' in homophones and homographs. This systematic Spanish feature is shown in a table. Some detailed reference to Venezuelan Spanish Intonation is made for two main reasons: (a) stress and intonation are intertwined, (b) intonation complements meaning. Samples of the Venezuelan Spanish Intonation illustrate its use in some common utterances.

Keywords: stress, system, intonation. cambio, cuento; aquellas en que cae sobre la antepenúltima sílaba, esdrújulas,

${ }^{1}$ Profesor de Inglés y Castellano, Master of Arts en Lingüística y Enseñanza del Inglés. Profesor de inglés en la UNEXPO, Jefe (E) del Departamento de Bienestar Estudiantil de la UNEXPO - Barquisimeto. Jefe de la sección de Lingüística del Departamento de Idiomas Modernos del IPB. Profesor de Fonética y Fonología del Inglés, Lingüística, Psicosociolingüística en el IPB. Premio "Luís Beltrán Prieto Figueroa”. Autor de "The Word in Connected Speech", "Contrasts Between the English and the Venezuelan Spanish Verb Phrase", "DICBIL" (Diccionario Bilingüe) en formato electrónico, "Un Curso para Iniciarse en la Comprensión Lectora en Inglés" en formato electrónico. Ponente invitado a las Jornadas de Profesores de Inglés de UPEL - IPB.Actualmente, Coordinador del Subprograma de Maestría "Enseñanza del Inglés como Lengua Extranjera".

En la obra 'Gramática de la Lengua Castellana’ de Bello y Cuervo (1945) se afirma que:

el acento consiste en una levísima prolongación de la vocal que se acentúa, acompañada de una ligera elevación del tono. Las vocales acentuadas se llaman agudas, y las otras graves. Las dicciones en que el acento cae sobre la última sílaba (que no es lo mismo que sobre la última vocal), se llaman también agudas, como varió, jabalí, corazón, veréis, fraguáis; aquellas en que cae sobre la penúltima sílaba, llanas o graves, como varío, conato, margen, peine, como líquido, lágrima, régimen, cáustico, diéresis; y en fin, aquellas en que sobre una sílaba anterior a la antepenúltima (lo que sólo sucede en palabras compuestas, es decir, en cuya formación han entrado dos o más palabras), sobreesdrújulas como cumpliéramoslo, daríamostela. (p. p. 30 - 32)

Por su parte, en una obra de data reciente, 'La Lengua como Sistema de Sistemas' (1994), la profesora Berta L. Cardona establece que:

las palabras, según el lugar que en ellas ocupe el acento se dividen en agudas u oxítonas; graves, - llanas o paroxítonas -; esdrújulas o proparoxítonas y sobreesdrújulas. A estas se les coloca una rayita oblicua

(') llamada tilde o acento gráfico sobre la vocal de la sílaba que se destaca, de acuerdo a reglas establecidas. (p. 22).

Luego continúa la autora con una serie de ejemplos de cada tipo de palabras e incluye una referencia al acento especial que se emplea para marcar el hiato, es decir, la ruptura de un diptongo; por ejemplo, ven - ní - a (ve - nia), con - ti - nú o (con - ti - nuo). Igualmente, incluye el concepto de acento diacrítico, el cual se emplea para distinguir palabras homógrafas y homófonas que pertenecen a clases distintas: 
C. f.

\begin{tabular}{l|l}
\multicolumn{1}{c|}{$\begin{array}{l}\text { pronombre } \\
\text { tú (caminativo }\end{array}$} \\
éste, ésta (fue electa) & tu (casa) \\
este (perro), esta (casa) \\
aquél, aquélla (cantó) & el (canto) \\
mí (pensaste en mí) & mi (pensamiento)
\end{tabular}

\begin{tabular}{c|c}
$\begin{array}{c}\text { pronombre / adverbio } \\
\begin{array}{l}\text { sí (volvió en sí) } \\
\text { sí lo logró } \\
\text { más (quiero más) }\end{array}\end{array}$ & $\begin{array}{c}\frac{\text { conjunción }}{\text { si te quedas, te regalo un dulce }} \\
\text { Mas sólo el que se esfuerza vence }\end{array}$ \\
\hline$\underline{\text { sólo (quería cantar) }}$ & $\begin{array}{c}\text { adjetivo } \\
\text { quería cantar solo }\end{array}$ \\
\hline$\underline{\text { sustantivo }}$ & $\begin{array}{c}\text { pronombre } \\
\text { te quiero }\end{array}$ \\
\hline sé (lo que quiero) & $\begin{array}{c}\text { veronombre } \\
\text { Juan se cayó }\end{array}$ \\
\hline dé (lo mejor de sí) & preposición \\
\end{tabular}

Y en una obra de data mucho más reciente, 'Gramática Lengua Española’ (Larousse 2000) se afirma que:

En una palabra las sílabas pueden ser tónicas o átonas, dependiendo de si tienen o no acento... El acento puede ser ortográfico o prosódico; el primero se escribe gráficamente, como por ejemplo en las palabras débiles, cálidas, acuáticas, razón, colibrí, dátil. El acento prosódico se pronuncia pero no se escribe, por ejemplo: cama, tigre, luz, paladar. (p. 13).
Al igual que en las otras obras mencionadas, en ésta también se establece que las palabras se clasifican en agudas, graves, esdrújulas y sobreesdrújulas, según el lugar donde se encuentre la sílaba tónica.

Al comparar las cuatro obras referidas, una idea resalta claramente: las palabras se clasifican según el lugar que ocupe el acento en una sílaba determinada. Sin embargo, tanto en la clasificación que hace la Real Academia como en la distinción que se hace sobre el uso del acento diacrítico subyace un rasgo que es importante para el presente trabajo: el uso del acento para distinguir; por ejemplo, si una palabra - homófona u homógrafa - es una forma verbal, un sustantivo o un adjetivo. Es decir, el acento tiene un valor sintáctico semántico que hasta ahora no se ha explicado con claridad, ni se ha hecho ver que la lengua española tiene mecanismos lingüísticos que aportan economía a su sistema lexical. Es decir, una misma forma lexical puede pertenecer y usarse como sustantivo, verbo (tiempo presente o pasado, cambiar de modo indicativo a subjuntivo) o adjetivo con sólo variar la posición relativa del acento en la palabra. Este uso del acento es reconocido por Bello y Rufino Cuervo cuando en la obra ya mencionada dicen:

... no importa menos atender al acento, que da a cada palabra una fisonomía, por decirlo así, peculiar, siendo él a veces la sola cosa que las diferencia unas de otras, como se notará comparando estas tres dicciones: vario, varío, varió, y estas otras tres: líquido, liquido, liquidó. (p. p 31- 30)

C. f.

\begin{tabular}{l|rrr|} 
& $\begin{array}{l}\mathrm{V} \\
\text { Sustantivo }\end{array}$ \\
$\begin{array}{l}\text { (el) paso (grave) } \\
\text { pérdida(esdrújula) }\end{array}$ & $\begin{array}{ll}\text { presente (indicativo) } \\
\text { (yo) paso (grave) }\end{array}$ & pasado (indicativo) & (él) pasó (aguda)
\end{tabular} \mid $\begin{aligned} & \text { adjetivo } \\
& \text { perdida(grave) }\end{aligned}$

Se afirma que el acento tiene un valor sintáctico - semántico porque entre una forma verbal como 'paso' (presente de indicativo, $1^{\text {a }}$ persona singular) y el sustantivo 'paso' (homófonos y homógrafos), la distinción está dada por el artículo 'él' que marca a 'paso' como sustantivo y el pronombre 'yo' marca a la misma forma como 'verbo'; lo cual queda confirmado al añadirle un complemento: (yo) 'paso al salón ahora'. Observemos que ambas formas son graves porque el acento recae sobre la penúltima sílaba lo que las hace homófonas y homógrafas; por lo tanto, el acento - en este caso - no establece la distinción gramatical sino el sintagma (construcción sintáctica). Sin embargo, el acento sí juega un papel importante para distinguir dos tiempos verbales del indicativo de 'pasar': 
presente simple (grave) / pasado simple (aguda) y dos personas gramaticales: $1^{\mathrm{a}} / 3^{\mathrm{a}}$, respectivamente. En el segundo ejemplo, la posición del acento es la única marca de diferencia semántica y gramatical entre las formas homógrafas 'pérdida' (sustantivo) y 'perdida' (adjetivo).

Otro caso donde la distinción se da sólo por el acento, es cuando, por ejemplo, dos formas verbales pertenecen a personas y tiempos verbales distintos.

\section{C. f.}

'ratifico' (presente de indicativo, $1^{\mathrm{a}}$ persona) / 'ratificó' (pasado indicativo, $3^{\mathrm{a}}$ persona) (grave)

$$
\text { (aguda) }
$$

A pesar de que en la obra de Bello y Cuervo se reconoce que el acento sirve para distinguir significado - aunque indirectamente - entre formas homófonas y / u homógrafas, no se provee una explicación un poco más extensa y formal sobre el empleo sintáctico semántico del acento. Este empleo del acento es mucho más consistente y formal de lo que aparentemente se cree. Veamos una serie de ejemplos de este uso en el Cuadro 1.

Cuadro 1

DISTRIBUCIÓN DEL ACENTO EN FORMAS VERBALES Y SUSTANTIVAS DEVERBALIZADAS

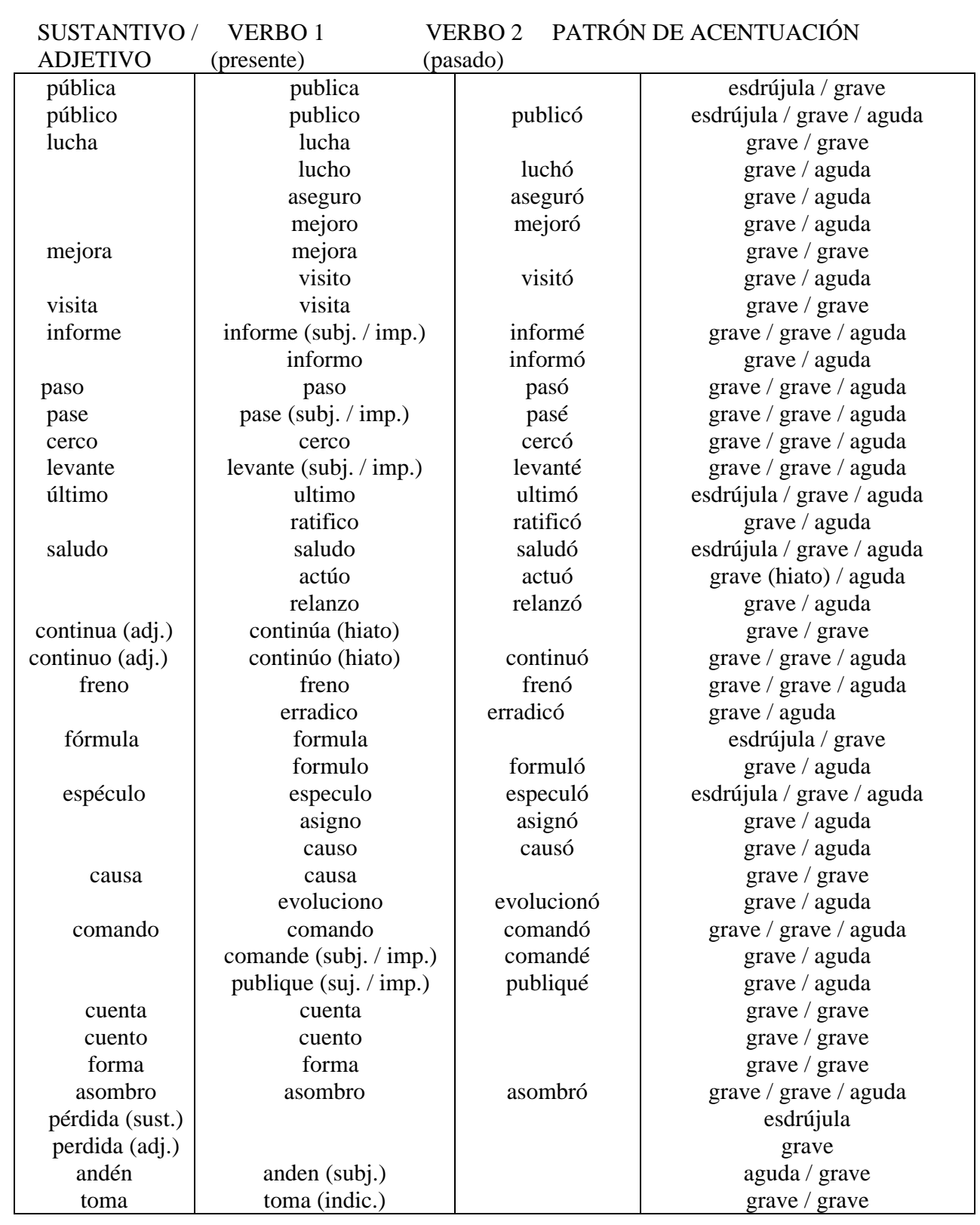

Se observa en el cuadro 1 presentado una constante en el uso del acento y su distribución en las sílabas para distinguir entre tiempos, personas y hasta modos verbales 
de las formas homófonas y / u homógrafas de un verbo; igualmente, el acento sirve para distinguir oposiciones entre 'sustantivo / verbo' y 'sustantivo / adjetivo'. Es de hacer notar que el acento no marca la oposición'sustantivo / verbo' entre formas 'homófonas graves'; en esta oposición juega un papel preponderante el 'artículo' que marca a la forma como 'sustantivo' y al 'sujeto' (nombre propio o pronombre) y 'complemento' que marcan a la forma homófona como 'verbo'. En contraste a lo dicho anteriormente, el acento tiene un rol preponderante para distinguir las oposiciones entre 'adjetivo / verbo' (continuo / continúo / continuó) y entre ‘sustantivo y adjetivo’ (pérdida / perdida).

Otra característica presente en el acento es un patrón de distribución muy marcado y constante en el verbo, es decir, el acento cubre un rango entre 'agudo', 'grave' y 'esdrújulo'. Por supuesto, este patrón puede ser alterado al emplearse una forma pronominal para formar, por ejemplo, los 'verbos reflexivos': 'caer (agudo) / caerSE' (grave) o cuando a una forma verbal se le añade una o dos formas pronominales como en 'daríamos’ (esdrújula) / 'daríamosla' (sobresdrújula) o ‘daríamostela'; casos estos, hasta el presente, no muy frecuentes en el uso oral diario del idioma; su uso es mayormente en el lenguaje escrito.

El cuadro 2 muestra un resumen del patrón de distribución del acento en el verbo español venezolano estándar o variedad de la región central de Venezuela que es la usada en radio y televisión como acento 'neutro' (en comparación con los dialectos zuliano, larense, oriental y los demás existentes en el español venezolano) y aceptada como forma educada por consideraciones socio-económico-políticas debido a que el poder político y económico está concentrado en esa región del país. La muestra es de esta variedad ya que existen otras, como el argentino donde; por ejemplo, las formas verbales pasa, ven y puedes (graves en el estándar venezolano) se pronuncian pasá, vení y podés (agudas) como formas escuchadas en televisión y radios argentinas (dicho sea de paso, estas voces son también empleadas en el dialecto larense).

\section{Cuadro 2}

\section{PATRÓN PROSÓDICO EN EL VERBO ESPAÑOL DE VENEZUELA}

\begin{tabular}{|c|c|c|}
\hline AGUDA $^{1}$ & GRAVE $^{3}$ & ESDRUJULA \\
\hline $\begin{array}{l}\text {-Infinitivo } \\
-1^{\mathrm{a}} \text { y } 3^{\mathrm{a}} \text { personas singular del } \\
\text { pretérito simple del indicativo } \\
\text {-Futuro simple (excepto la } 1^{\mathrm{a}} \\
\text { persona plural del indicativo }{ }^{2} \text { ) }\end{array}$ & 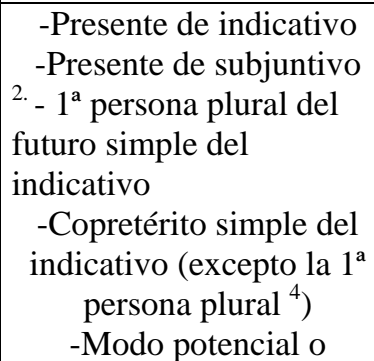 & $\begin{array}{l}4 .-1^{\text {a }} \text { persona plural del } \\
\text { copretérito, modo indicativo } \\
5 .-1^{\text {a }} \text { persona plural del modo } \\
\quad \text { potencial o condicional } \\
6 .-1^{\text {a }} \text { persona plural del } \\
\text { copretérito del modo } \\
\text { subjuntivo } \\
7 .-1^{\text {a }} \text { persona plural del } \\
\text { futuro simple del modo }\end{array}$ \\
\hline
\end{tabular}

\begin{tabular}{|c|c|c|}
\hline & 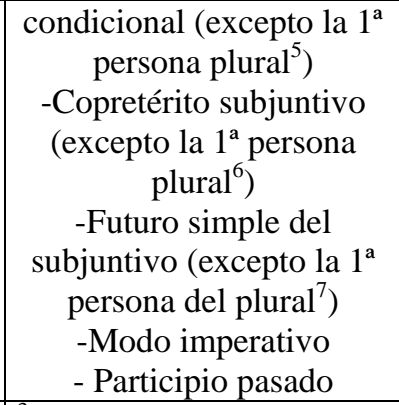 & subjuntivo \\
\hline $\begin{array}{l}\text { 1. Todas la formas verbales } \\
\text { monosilábicas, } \\
\text { independientemente del } \\
\text { número (singular / plural), del } \\
\text { modo (indicativo / subjuntivo / } \\
\text { potencial - o condicional / } \\
\text { imperativo) o tiempo verbal } \\
\text { son agudas por definición. Por } \\
\text { ejemplo, 'saber / se', 'haber / } \\
\text { he', 'ver / ve, vio’; 'ir / ve’, } \\
\text { 'dar / den, da, dio, das' }\end{array}$ & $\begin{array}{l}\text { 3. Las formas reflexivas } \\
\text { del infinitivo son graves }\end{array}$ & $\begin{array}{c}\text { N. B. También son } \\
\text { esdrújulas o sobreesdrújulas } \\
\text { las formas verbales con una o } \\
\text { dos formas pronominales } \\
\text { enclíticas, respectivamente. } \\
\text { (ver ejemplos en el texto) }\end{array}$ \\
\hline
\end{tabular}

Observamos, a partir del cuadro resumen anterior, la marcada distribución del acento en tres de cuatro posiciones silábicas posibles que sirve para establecer, en forma económica, distinciones sintáctico-semánticas. Dicha distribución ayuda a la comunicación al establecer diferencias entre formas homógrafas y homónimas, como ya se ha establecido por medio de los ejemplos ofrecidos.

Junto al acento existe otra característica lingüística que se combina con este: la entonación, que también asiste a la semántica y a la sintaxis en el acto comunicativo. Tanto el acento como la entonación forman parte del componente suprasegmental del lenguaje.

¿Qué importancia tiene la entonación para el acto comunicativo? Una respuesta es que la entonación tiene usos semánticos y sintácticos que sirven para obtener o deducir información más allá de las palabras y sintagma.

La entonación sirve desde el punto de vista semántico para que el oyente deduzca, por ejemplo, el estado anímico de un interlocutor: si está compungido, si está preocupado, si está alegre, si está enojado, si está centrado y otros estados del ánimo. Goleman (1997), en su libro Emotional Intelligence afirma que la amygdala es la especialista para los asuntos emocionales y que cuando ésta es extirpada, el resultado es una inhabilidad para juzgar o valorar la significación emocional de situaciones emocionales, es decir, la persona se torna 
alexitímica o ciega emocional. La entonación es lo que se llamaría el componente emocional del lenguaje. A este componente se recurre en momentos de duda acerca del mensaje recibido para componer una respuesta adecuada a la situación sociolingüística que se vive en un momento dado, ya que el oyente pone mayor atención a la parte suprasegmental para su accionar o reaccionar. Es decir, la sintaxis es importante para estructurar un mensaje pero la entonación adorna el mensaje y a dicho adorno se responde o se le pone mayor atención para determinar qué curso de acción tomar en un acto comunicativo. Es por ello que podríamos acuñar un término: ‘uso parasemántico’ ya que la entonación no posee significado por sí misma si no se ejecuta sobre un componente fonológico o sintáctico: / $\mathrm{m} /$ con el tono de voz en alza se puede entender como una pregunta, / S / con la voz en bajada se puede entender como 'silencio' de manera imperativa; / me gusta ese/ con la voz en bajada en el pronombre se entiende como una aseveración; mientras que la misma frase con la voz en subida: /me gusta ese/ se puede entender como una pregunta.

En cuanto al uso sintáctico de la entonación; tenemos que, entre otros, sirve para señalar a un oyente que se va cerrar la intervención en un diálogo o que se va a interrumpir al interlocutor para hacer una acotación. Sirve para indicar si se va a continuar la intervención porque se va a añadir información nueva a la que ya se ha dado. Otro uso, sintáctico -semántico, es para indicar que se está haciendo una pregunta o que se está respondiendo o afirmando. En cuanto al acto de habla en sí (acto elocutivo) - incluyendo la lectura de textos - sirve para agrupar la cantidad de sílabas que forman un grupo de habla que posee sentido, aún cuando ese grupo no cumpla con los cánones de lo que se considera normalmente una oración completa. También podríamos acuñar otro término: 'uso parasintáctico'; es decir, si bien la entonación no forma parte del sintagma en forma lineal como lo hacen las llamadas partes del habla, sí co-ocurre con el sintagma de manera simultánea: ni antes del sintagma, ni después de éste, sino en el momento de emisión. La entonación es parte del sintagma como sobre imposición al mismo. Su empleo es paralingüístico.

Sin embargo, la entonación en español venezolano no obedece a patrones - no se puede distribuir como se hace con el acento - ya que ella consiste simplemente en hacer subir o bajar el tono de la voz para transmitir un efecto al oyente. Es decir, a pesar de que el tono de voz puede subir o bajar en la sílaba tónica; no se puede dictaminar que en una sílaba tónica dada se debe bajar o subir el tono de voz - que sería el patrón - porque el español no es un idioma tonal, como el chino, donde la entonación tiene un valor semántico distintivo. La entonación la maneja el hablante para transmitir efectos junto al mensaje que portan las palabras en un sintagma. Como se mencionó anteriormente.

Lo que sí se puede determinar es el rango de altura, o nivel del tono, que puede alcanzar la voz en español venezolano. A continuación presentamos un gráfico que ilustra la distribución de la altura del tono de voz en español venezolano, seguido de unos ejemplos, por medio de un corpus, que demuestran su empleo en el habla. (Milano 2001):

ESPAÑOL VENEZOLANO

enfático

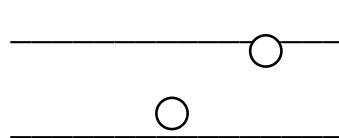

alto

normal o medio

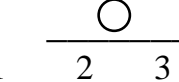

Los números debajo de las líneas que representan el nivel de altura del tono de voz significan lo siguiente: 1 , tono bajo; 2 , tono normal o medio y 3 , tono alto. Al pasar este tono se está en el rango enfático. Las flechas señalan el término del tono.

He aquí unos ejemplos que muestran su uso normal en expresiones comunes en español venezolano, es decir, sin añadidos de significado al mensaje original:

1. Aseveraciones y preguntas para pedir información:

2 11

Soy de Venezuela

$12 \quad 11$

¿De dónde vienes?

$\begin{array}{lll}2 & 1 & 1\end{array}$

¿Cómo se llama?

2. Preguntas con respuestas si / no y preguntas de eco (pedir repetición):

$2 \quad 2 \quad 2$

¿Va al centro?

222

¿Cómo se llama? † (pidiendo repetición) 
3. Aseveraciones enfáticas o contrastantes de preguntas de información:

\begin{tabular}{|c|c|c|}
\hline \multirow{2}{*}{\multicolumn{2}{|c|}{$\begin{array}{l}2 \\
\text { No soy de Aruba }\end{array}$}} & 2 \\
\hline & & Spy de Jamaic \\
\hline 22 & 21 & $2 \downarrow$ \\
\hline ¿Sábado? & No & Hoy es domingo \\
\hline 21 & 11 & 31 \\
\hline
\end{tabular}

4. Vocativos y otros modificadores de expresiones:

21111

Hola, María

$\begin{array}{llllll}12 & 11 & 1 & \mathbf{Y} & 1 & 1\end{array}$

Estoy bien, muchas gracias

5. Saludos:

121

Adiós

Hasta mañana

231

211

Qué tal (đon entusiasmo) o Qué tal

6. Enumeración:

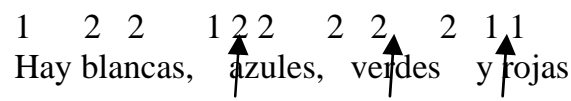

\section{REFERENCIAS}

Bello, A. \& Cuervo, R. (1945). Gramática de la Lengua Castellana. Argentina: Editorial Sopena

Cardona, B. (1994). La Lengua como Sistema de Sistemas, Comunicación y Lenguaje. Maracaibo: Ediluz.

Chela de Rodríguez, B. (1980). La Enseñanza de los Suprasegmentos del Inglés a Hispano parlantes en Revista Lingua $N^{o}$ 1. Maracaibo: Universidad del Zulia

Goleman, D. (1997). Emotional Intelligence. Bantam Books

Larousse (2000). Gramática Lengua Española. México.

Learning Network (2006). Dictionary on line. Disponible:
http://www.infoplease.com/ipd/A06051123 [Consulta 2006, enero 20]

Milano, A. (2001). Why intonation in an English as a second/ foreign language course. Trabajo no publicado. Barquisimeto

Real Academia Española (1931) Gramática de la Lengua Española. Madrid. 